\title{
LIFE ON THE ROCKS: HABITAT USE DRIVES MORPHOLOGICAL AND PERFORMANCE EVOLUTION IN LIZARDS
}

\author{
Brett A. Goodman, ${ }^{1,3}$ Donald B. Miles, ${ }^{2}$ and Lin Schwarzkopf ${ }^{1}$ \\ ${ }^{1}$ School of Marine and Tropical Biology, James Cook University, Townsville 4812, Queensland, Australia \\ ${ }^{2}$ Department of Biological Sciences, Ohio University, Athens, Ohio 45701 USA
}

\begin{abstract}
As a group, lizards occupy a vast array of habitats worldwide, yet there remain relatively few cases where habitat use (ecology), morphology, and thus, performance, are clearly related. The best known examples include: increased limb length in response to increased arboreal perch diameter in anoles and increased limb length in response to increased habitat openness for some skinks. Rocky habitats impose strong natural selection on specific morphological characteristics, which differs from that imposed on terrestrial species, because moving about on inclined substrates of irregular sizes and shapes constrains locomotor performance in predictable ways. We quantified habitat use, morphology, and performance of 19 species of lizards (family Scincidae, subfamily Lygosominae) from 23 populations in tropical Australia. These species use habitats with considerable variation in rock availability. Comparative phylogenetic analyses revealed that occupation of rock-dominated habitats correlated with the evolution of increased limb length, compared to species from forest habitats that predominantly occupied leaf litter. Moreover, increased limb length directly affected performance, with species from rocky habitats having greater sprinting, climbing, and clinging ability than their relatives from less rocky habitats. Thus, we found that the degree of rock use is correlated with both morphological and performance evolution in this group of tropical lizards.
\end{abstract}

Key words: adaptation; comparative method; ecomorphology; habitat use; lizard; locomotion; performance; physiological ecology; rock use; Scincidae.

\section{INTRODUCTION}

For animals, effective movement within the environment is critical for prey capture, predator escape, and mate acquisition (Turchin 1998). Therefore, variation in locomotion can potentially influence growth rates, survival, and reproduction (Arnold 1983, Garland and Losos 1994, Irschick and Garland 2001), and numerous studies have examined differences in locomotor performance among individuals and species (see reviews in Garland and Losos 1994, Irschick and Garland 2001). The environment through which movement must occur, therefore, should be a critical determinant of the morphology of, species, populations, and individuals (Losos 1990, Losos et al. 1997, Van Damme et al. 1998, Vervust et al. 2007). Whereas various studies have examined and identified relationships between morphology and ecology (Miles and Ricklefs 1984, Pounds 1988, Herrel et al. 2002, reviewed in Garland and Losos 1994, Irschick 2002), relatively few have examined the relationship between habitat use and performance (Losos 1990, Irschick and Losos 1999, Melville and Swain 2000, Vanhooydonck and Van Damme 2003, Mattingly and Jayne 2004). The assumption that

Manuscript received 20 December 2007; revised 7 March 2008; accepted 7 April 2008. Corresponding Editor: A. M. Bronikowski.

${ }^{3}$ E-mail: Brett.Goodman@jcu.edu.au performance is optimized in specific habitats remains untested for most habitat types. Thus, measuring habitat use in a wide range of habitats in the field, and correlating it with performance in the laboratory, is a fertile area for research into adaptation to environments (Huey 1991, Garland and Losos 1994, Irschick and Losos 1999, Irschick 2002).

As a group, lizards have been useful subjects for establishing adaptive links between morphology, locomotor performance, and habitat use. Among the clearest ecomorphological relationships to emerge has been the pattern of diversification of the Greater Antillean arboreal anoles (Moermond 1979, Losos 1990, Irschick et al. 1997). Anoles partition their environment to avoid competition, with limb length responding to shifts in perch diameter (Losos 1990, 1995, Irschick et al. 1997, Irschick and Losos 1999), and these differences in relative limb length strongly determine such performance traits as running, clinging, and jumping (Losos 1990, Irschick et al. 2005). While there is some evidence of morphological evolution of lizards from some groups (i.e., Ctenotus, Niveoscincus) in response to differences in habitat openness (Pianka 1969, Garland and Losos 1994, Melville and Swain 2000), an obvious suite of predictable traits does not seem apparent for lizards from other groups from different substrates (Vanhooydonck and Van Damme 1999, Herrel et al. 2002), with different escape strategies, or that possess armature 
(Losos et al. 2002, Schulte et al. 2004). One morphologically demanding habitat used by many animals, including lizards, is rocky environments. Animals that use rocky habitats must climb vertical surfaces, jump gaps between adjacent rocks, and take refuge in narrow crevices. Further, individuals climbing steep inclined surfaces often experience reduced maximal speeds and acceleration, and increased energetic costs (Taylor et al. 1972, Farley and Emshwiller 1996, Irschick and Jayne 1998). Thus, in habitats where individuals often climb on broad, inclined surfaces, selection should favor morphologies that promote greater climbing ability. Rocky habitats are composed of many broad, inclined surfaces, often consisting of large areas with minimal cover or vegetation, and where the risk of predation is greatly increased, which places greater demands on the locomotor performance of species to cover such areas quickly. As such, it seems reasonable to predict that rocky habitats should place intense functional, ecological, and therefore, selective demands on the species that occupy them (Vitt et al. 1997, Revell et al. 2007). Thus, an examination of the morphological, locomotory performance, and habitat use relationships among model organisms that use environments containing different proportions of rocks is warranted.

We quantified microhabitat use, locomotor performance (running, jumping, climbing, clinging), and morphology in 19 species of lizard from 23 populations of the subfamily Lygosominae (family Scincidae). We tested the hypothesis that species inhabiting increasingly rocky environments will exhibit evolutionary shifts in morphology that enhance performance at ecologically relevant locomotor modes. The species in our sample occur in a range of habitats (Ingram and Covacevich 1988, 1989, Cogger 2000), and recent work found that these species display considerable overlap in habitat use, yet use available microhabitats nonrandomly (Goodman 2007a). We sampled species from a variety of habitats ranging from those completely composed of rocks (boulder fields) to sites predominantly composed of leaf litter with a few rocks protruding from soil (leaf litter habitats). The existence of nonrandom habitat use among these species (Goodman 2007a) suggests that these species use microhabitats in which performance is optimized, given interspecific and intersexual competitive interactions. Thus, lizards of this group provide an excellent model system with which to examine patterns of morphological evolution in response to variation in habitat characterized, at least in part, by differences in the amount of rock use.

\section{Methods}

\section{Study system}

We examined 19 species of lizards, from 23 populations, in the following genera: Carlia (11 species; 15 populations), Cryptoblepharus (2 species), Eulamprus (2 species), Lampropholis (3 species), and Techmarscincus (1 species; formerly the genus Bartleia). The members of the subfamily Lygosominae occupy a range of habitat types, including limestone outcrops, boulders, cloud forest, open monsoon forest, and rainforest (see Goodman 2007a for details on study sites and habitats). To examine intraspecific variation in habitat use, morphology, and locomotory performance, we sampled three populations of Carlia rubrigularis near Cairns, Queensland, Australia, that occupy structurally different habitats at different elevations and represent distinct genetic lineages (Phillips et al. 2004, Dolman and Moritz 2006). Previous work has shown that different levels of habitat openness is often correlated with morphological divergence among populations of Carlia rubrigularis (Schneider et al. 1999). We also included three populations of Carlia longipes: two populations near Cooktown separated by $18 \mathrm{~km}$ that occupy markedly different habitats (rocky outcrops vs. open woodland) and a third population that occupies anthropomorphically modified open woodland habitat at Wonga Beach, $85 \mathrm{~km}$ north of Cairns.

\section{Measuring lizard microhabitat occupation}

The structural microhabitat of each species was characterized by walking randomly located transects of $100 \mathrm{~m}$ through each species' habitat between 10:00 and 17:00 hours Australian Eastern Standard Time (AEST), when most lizards are active. For undisturbed individuals of each species, we recorded the substrate or perch type, perch angle, and perch height above the ground. The following data was also recorded in a $3-\mathrm{m}$ radius around each lizard: percent total ground cover, percent total rock cover, percent leaf litter cover, percent bare earth, percent logs, percent rocks $<0.5 \mathrm{~m}^{3}$, and percent rocks $>0.5 \mathrm{~m}^{3}$.

\section{Lizard collection and husbandry}

Adult male individuals of each species were collected by hand, using baited sticky traps, or with pit-fall traps modified for rocky habitats (Goodman and Peterson 2005). In this study, we focused on males, the sex in which performance is most strongly related to fitness (Huyghe et al. 2005, Husak et al. 2006). See Goodman et al. (2007) for details on husbandry.

\section{Morphological measurements}

The following morphological traits were measured directly from live lizards using digital callipers $( \pm 0.01$ $\mathrm{mm}$ ): snout-to-vent length, inter-limb length, head width, head height, forelimb length, hind-limb length, and tail length (if regenerated, both the original and regenerated tail portions). In addition, each individual was radiographed to provide precise measurements of the length of limb elements (e.g., radio-ulna, humerus, tibio-fibula, and femur). See Goodman et al. (2007) for details. See also Appendix A.

\section{Measures of performance}

We measured the locomotory performance of individuals of each species at four tasks, including sprinting, 
TABLE 1. Principal components (PC) analysis on the independent contrasts of the habitat use of 23 populations of tropical lygosomine skinks from northern Australia.

\begin{tabular}{lrr}
\hline \hline Morphological trait & PC1 & PC2 \\
\hline Body/perch angle & 0.547 & -0.318 \\
Total ground cover & $\mathbf{- 0 . 9 5 9}$ & -0.122 \\
Cumulative rock & $\mathbf{0 . 9 4 1}$ & -0.107 \\
Percent leaf litter & $-\mathbf{0 . 9 0 3}$ & -0.213 \\
Percent bare earth & -0.302 & 0.269 \\
Percent log & -0.158 & 0.385 \\
Percent rock $<50 \mathrm{~cm}$ & 0.192 & $\mathbf{0 . 8 1 8}$ \\
Percent rock $>50 \mathrm{~cm}$ & $\mathbf{0 . 8 7 4}$ & -0.330 \\
Height above substrate & $\mathbf{0 . 6 9 5}$ & -0.362 \\
Weighted microhabitat & $\mathbf{- 0 . 7 8 8}$ & 0.319 \\
\hline
\end{tabular}

Notes: The number of PC axes retained for use in subsequent analyses was determined using a scree plot of the eigenvalues (Jackson 1993). Variables with correlations greater than \pm 0.5 are highlighted in boldface. For PC1, the eigenvalue is 5.1, with $50.9 \%$ of the variation explained; for PC2, the eigenvalue is 1.3 , with $12.6 \%$ of the variation explained.

climbing, clinging, and jumping. See details in Goodman et al. (2007) and the summary table of mean performance traits (Appendix B).

\section{Analyses}

Phylogeny.-Details on the phylogeny used for comparative analyses in this paper is provided elsewhere (Appendix C).

Phylogenetic analyses.-As a high proportion of the morphological traits of the species examined in this study exhibit significant phylogenetic signal (Goodman et al. 2007), we used phylogenetic comparative methods to examine relationships between morphology, performance, and habitat use. Mean values for each morphological measure for each species were $\log _{10}$-transformed to achieve normality prior to analyses (Sokal and Rohlf 1995). We used the module PDTREE in the program PDAP to calculate standardized independent contrasts of all morphological, ecological, and performance measures (Garland et al. 1992). Contrasts of trait values were checked for adequacy of standardization by dividing the independent contrast of each trait by the standard deviation of the branch length (square root of the corrected branch length) of that trait (Garland et al. 1992). We tested that branch lengths were adequately standardized using both statistical correlations and visual inspection of all diagnostic plots. As there were no significant linear or nonlinear trends in the data $(r=$ -0.26-0.08; all $P$ values $>0.24$ ), all branch lengths were deemed adequately standardized as required under a Brownian motion model of evolution. We then developed standardized (size-corrected) independent contrasts of all morphological and performance traits by regressing (through the origin) the standardized independent contrast of each performance trait against the standardized independent contrast of snout-to-vent length (Garland et al. 1999).

To reduce dimensionality of the habitat and sizecorrected morphological data sets, we used principal component (PC) analyses based on the correlation matrix (calculated through the origin) of independent contrasts of each trait as input. Previous work has demonstrated that the procedural order of this approach does not affect results (Zani 2000). The number of PC axes used in subsequent analyses was determined from a scree plot of the eigenvalues (Jackson 1993).

Next, we tested for relationships between performance and habitat use by comparing the independent contrasts of each performance trait separately against each habitat use axis using Pearson product-moment correlations. Finally, canonical correlations were used to assess the relationship between habitat use PC axes and the four performance measures, between morphology PC axes and the habitat use PC axes, and between morphology PC axes and the four performance measures examined for each species (Miles and Ricklefs 1984, Losos 1990).

\section{Results}

\section{Habitat use and rockiness}

The first two axes from a PC analysis based on the independent contrasts of habitat use variables explained $63.5 \%$ of the total variation. A scree plot of eigenvalues indicated the first two PC axes were most informative (Table 1). PC axis 1 explained $50.9 \%$ of the variation in independent contrasts of the raw habitat data and described a gradient of habitat occupancy with species that were observed on perches high above the substrate in boulder fields with large rocks at the positive end and ground-dwelling species that favored leaf litter microhabitats, i.e., large amounts of leaf litter and ground cover were at the negative end. The second PC axis explained $12.6 \%$ of the variation in the independent contrasts of the raw habitat data and described a gradient of species that occupied habitats with limited cover by small rocks to those that occupied habitats with a large amount of small rocks (positive loadings) (Table 1).

\section{Morphology}

A scree plot of eigenvalues indicated that the first two PC axes were most informative and explained $81.5 \%$ of the variation within the independent contrasts of sizecorrected morphology data. The first PC axis described $56.7 \%$ of the variation in the size-corrected morphology data, and high positive values on the first axis were associated with species with long forelimbs, hind limbs, and limb elements (Table 2), while high negative values on the first PC axis included species with short bodies (short inter-limb length) (Table 2). The second PC axis described $24.8 \%$ of the variation in the independent contrasts of size-corrected morphology data, with high positive values on the second axis denoting species with robust body shapes (high and wide bodies) (Table 2). In other words, the first two $\mathrm{PC}$ axes revealed an evolutionary change in limb length (PC1) and a change in body height (PC2). 
TABLE 2. Principal components analysis on the independent contrasts of the size-corrected morphological traits for 23 populations of tropical lygosomine skinks from northern Australia.

\begin{tabular}{lrr}
\hline \hline Morphological trait & \multicolumn{1}{c}{ PC1 } & PC2 \\
\hline Inter-limb length & $-\mathbf{0 . 6 1 1}$ & -0.328 \\
Head width & 0.301 & $\mathbf{0 . 8 3 4}$ \\
Head height & 0.107 & $\mathbf{0 . 9 3 1}$ \\
Body width & 0.140 & $\mathbf{0 . 7 6 9}$ \\
Body height & -0.030 & $\mathbf{0 . 9 4 0}$ \\
Forelimb length & $\mathbf{0 . 9 5 5}$ & 0.022 \\
Hind-limb length & $\mathbf{0 . 9 1 8}$ & 0.234 \\
Femur length & $\mathbf{0 . 9 0 7}$ & 0.218 \\
Humerus length & $\mathbf{0 . 9 4 4}$ & 0.108 \\
Radio-ulna length & $\mathbf{0 . 8 9 6}$ & -0.049 \\
Tibio-fibula length & $\mathbf{0 . 9 5 2}$ & 0.177 \\
\hline
\end{tabular}

Notes: The number of PC axes retained for use in subsequent analyses was determined using a scree plot of the eigenvalues (Jackson 1993). Variables with correlations greater than \pm 0.5 are highlighted in boldface. For PC1, the eigenvalue is 6.24 , with $56.7 \%$ of the variation explained; for PC2, the eigenvalue is 2.73 , with $24.8 \%$ of the variation explained.

\section{Habitat-morphology relationships}

Habitat use PC1 was significantly positively related to morphology PC1 (Fig. 1), suggesting that an increased use of rocky habitat is related to the evolution of relatively longer limbs and limb elements (positive loadings on morphology PC1). However, habitat PC2 was not significantly related to any of the morphology PC axes (Table 3).

\section{Morphology-performance relationships}

A comparison of the independent contrasts of sprinting performance and Morphology PC1 were positively related, but only marginally significant $(r=$ $0.38, P=0.056$; Fig. 2a), suggesting that other aspects of morphology, such as a more robust body shape may be important for attaining greater sprint speed (see canonical correlation section below). A comparison of the independent contrasts of all four performance tasks and morphology PC1 contrasts revealed that climbing (Fig. 2b) and clinging (Fig. 2c) were positively and significantly related to an increase in relative limb length (morphology PC1 contrasts; all $P$ values $<0.001$ ). Taken together, these results suggest that increased rock use has led to the evolution of increased limb length and enhanced sprinting, climbing, and clinging, but not jumping, in this clade of lizards (Fig. 2d).

\section{Habitat-performance relationships}

A comparison of the independent contrasts of the performance tasks and habitat use contrasts revealed that sprinting, climbing, and clinging were all positively and significantly related to the occupation of habitats dominated by large rocks (habitat PC1 contrasts; all $P$ values $<0.05$; Fig. $3 \mathrm{a}-\mathrm{c})$. However, jumping ability was unrelated to habitat use $(r=-0.14, P>0.54$; Fig. 3d).

\section{Canonical correlation of relationships between habitat use, morphology, and performance}

There were significant canonical correlations between habitat and performance, morphology and performance, and habitat and morphology. In each of these analyses, the first canonical axis, and the second axis in the morphology and performance analysis, were significant (Table 3). The first significant canonical axis of the habitat-morphology analyses (Table 4) indicates a relationship between the use of large rocks, perch height, and amount of rocks, leaf litter, and ground cover (habitat PC1) and increased length of the limbs and limb elements (morphology PC1; see Plate 1). The first axis of the habitat-morphology analyses (Table 4) indicates a relationship between limb length (morphology PC1) and body shape (morphology PC2) and sprinting, climbing, and clinging. The second canonical axis indicates a relationship not suggested from the analysis of habitat, between body shape (morphology PC2), and sprinting and clinging (Table 4). The significant canonical axis of the habitat-performance analyses (Table 4) indicates a relationship between the use of large rocks, perch height, and amount of rocks, leaf litter, and ground cover (habitat PC1) and sprinting, climbing, and clinging.

\section{DisCUSSION}

Our analyses revealed a clear evolutionary shift in both morphology and performance in response to the increased use of rocky habitats in our sample of lygosomine skinks. That is, species that occupied rocky habitats were faster at sprinting and climbing, and better

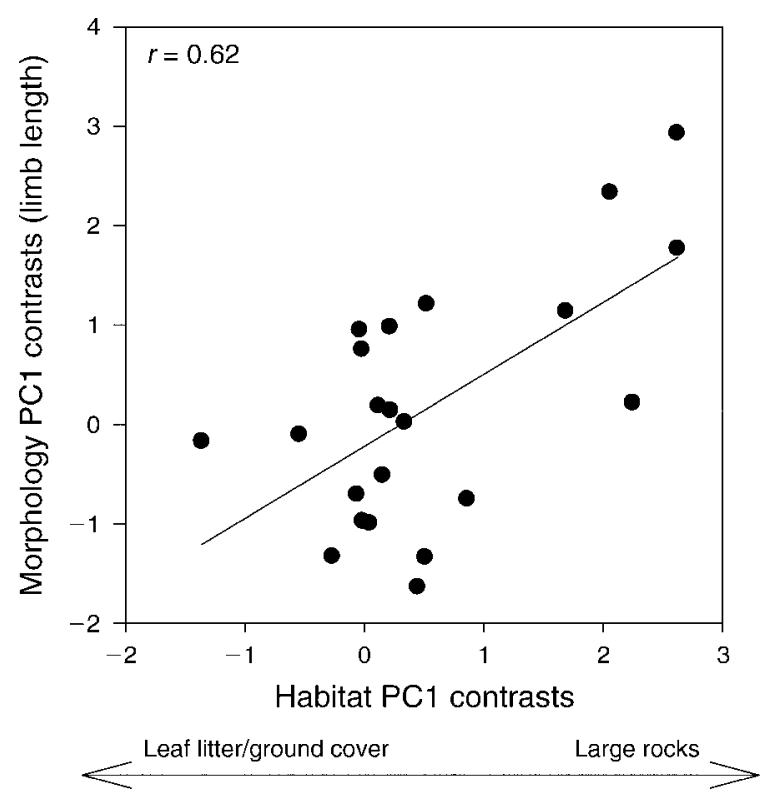

FIG. 1. Correlations between morphology $\mathrm{PC} 1$ and habitat PC1 for 19 species represented by 23 populations of tropical scincids (lygosomine skinks) examined in this study in northern Australia. 
TABLE 3. Results from canonical correlation analyses of habitat PCs and morphology PCs, morphology PCs and performance traits, and performance traits and habitat use.

\begin{tabular}{lccccrr}
\hline \hline Trait & $\begin{array}{c}\text { Canonical } \\
\text { axis }\end{array}$ & $\begin{array}{c}\text { Canonical } \\
\text { correlation }\end{array}$ & $\begin{array}{c}\text { Canonical } \\
R^{2}\end{array}$ & $\chi^{2}$ & df & $P$ \\
\hline a) Habitat PCs-morphology PCs & 1 & 0.70 & 0.49 & 12.28 & 4 & 0.015 \\
b) Morphology PCs-performance traits & 1 & 0.93 & 0.86 & 45.34 & 8 & $<0.001$ \\
& 2 & 0.69 & 0.48 & 11.40 & 3 & 0.010 \\
c) Habitat PCs-performance traits & 1 & 0.85 & 0.72 & 26.70 & 8 & $<0.001$ \\
\hline
\end{tabular}

Note: Only significant canonical axes are presented.

at clinging, compared to species from leaf litterdominated habitats that rarely use rocks. The increased use of rocky habitats, and increased selection for enhanced sprinting, climbing, and clinging, in these habitats has apparently selected for longer limbs in this group of lizards.

\section{Rock use as a selective gradient}

Our study identified a positive relationship between climbing speed and rock use for this group of tropical skinks. Similarly, in Anolis lizards, wider perches, and the associated possibility for fast movement when the perch is less precarious, has lead to the evolution of increased limb length and faster climbing performance (Losos and Sinervo 1989, Losos 1990, Losos and
Irschick 1996, Irschick et al. 1997). However, in anoles and other arboreal perch climbing lizards, climbing speed trades off with sprint speed on narrow perches: species that climb fast sprint more slowly (Losos and Sinervo 1989, Sinervo and Losos 1991). In contrast, skinks from rocky habitats showed positive correlations between sprint speed and climbing speed. This lack of a trade-off between sprinting and climbing performance highlights an apparent fundamental difference between organisms that climb perches compared to species that climb on broad substrates (see also Vanhooydonck and Van Damme 2001, Goodman et al. 2007). Organisms can use identical sets of movements when sprinting and climbing: species sprinting on a broad, horizontal surface or climbing on a broad, angled surface both
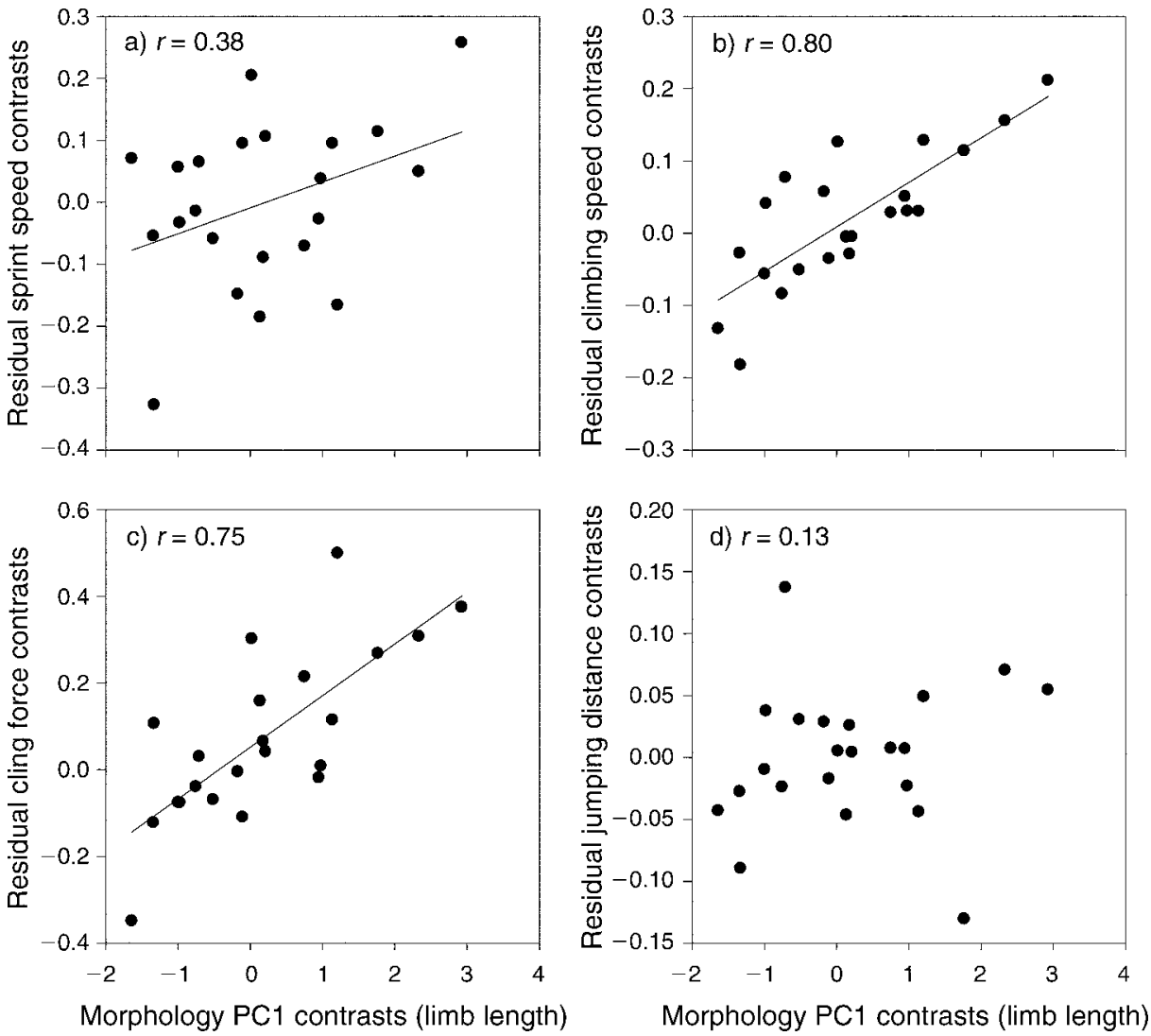

FIG. 2. Correlations between performance measures and morphology PC1, representing a gradient of increasing fore- and hindlimb length (limb length) for 19 species represented by 23 populations of tropical scincids examined in this study. 

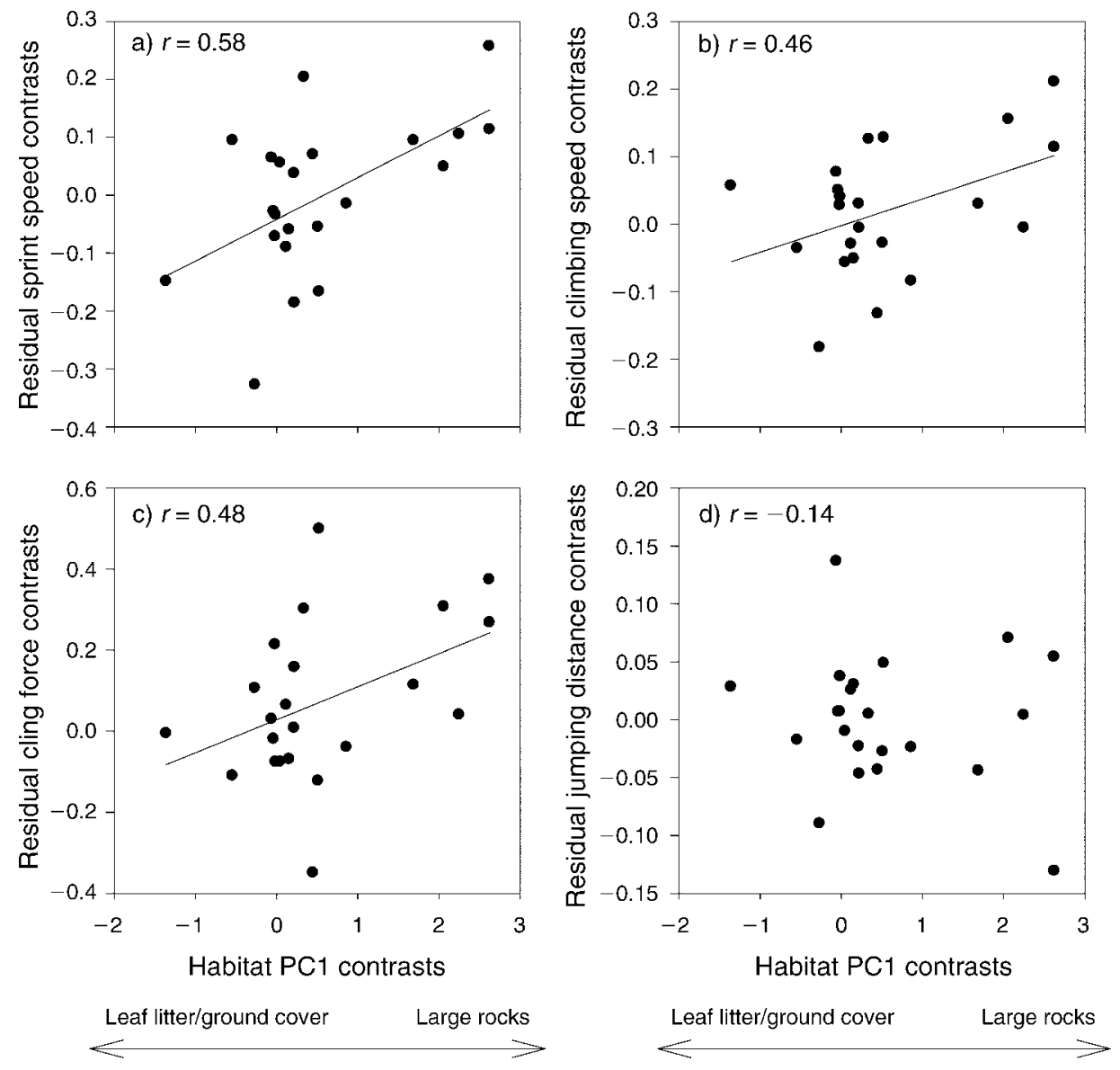

FIG. 3. Correlations between performance measures and a gradient of habitat use ranging from rocks to leaf litter for 19 species represented by 23 populations of tropical scincids examined in this study.

extend their limbs laterally to maintain their center of mass (and balance) close to the substrate (Vanhooydonck and Van Damme 2001). This contrasts with the benefit of short limbs for maintaining the center of mass directly above a narrow perch, where long limbs would increase the distance the center of mass is away from the perch, and thus, increasing the chance of toppling (Losos and Sinervo 1989, Sinervo and Losos 1991). Therefore, specialization for climbing on narrow perches causes trade-offs with movement on broad surfaces, whereas climbing broad surfaces does not cause tradeoffs with sprinting on flat surfaces.

\section{Behavioral effects on morphology- performance relationships}

Interestingly, in this group of skinks, we found no relationship between rock use and jump performance, although jumping is an important performance feature

TABLE 4. The proportion of variance explained by each of the significant canonical correlations (CC) axes in the analyses of sizefree phylogenetic independent contrasts of morphology and habitat use PC axes, and of each of the performance measures examined in this study.

\begin{tabular}{|c|c|c|c|c|c|c|c|c|}
\hline \multirow[b]{2}{*}{ Contrasts and $\mathrm{CC}$ axis } & \multicolumn{2}{|c|}{ Habitat } & \multicolumn{2}{|c|}{ Morphology } & \multicolumn{4}{|c|}{ Performance } \\
\hline & $\mathrm{PC} 1$ & $\mathrm{PC} 2$ & $\mathrm{PC} 1$ & $\mathrm{PC} 2$ & Sprinting & Climbing & Clinging & Jumping \\
\hline \multicolumn{9}{|l|}{ a) Habitat-morphology } \\
\hline $\mathrm{CCl}$ & 0.927 & 0.474 & 0.961 & 0.581 & $\cdots$ & $\cdots$ & $\cdots$ & $\cdots$ \\
\hline \multicolumn{9}{|l|}{ b) Morphology-performance } \\
\hline $\mathrm{CC} 1$ & $\cdots$ & $\cdots$ & 0.904 & 0.705 & 0.679 & 0.939 & 0.629 & 0.255 \\
\hline $\mathrm{CC} 2$ & $\cdots$ & $\cdots$ & 0.427 & 0.710 & 0.528 & 0.013 & 0.748 & 0.267 \\
\hline \multicolumn{9}{|l|}{ c) Habitat-performance } \\
\hline $\mathrm{CCl}$ & 0.999 & 0.078 & $\ldots$ & $\ldots$ & 0.678 & 0.527 & 0.561 & 0.177 \\
\hline
\end{tabular}



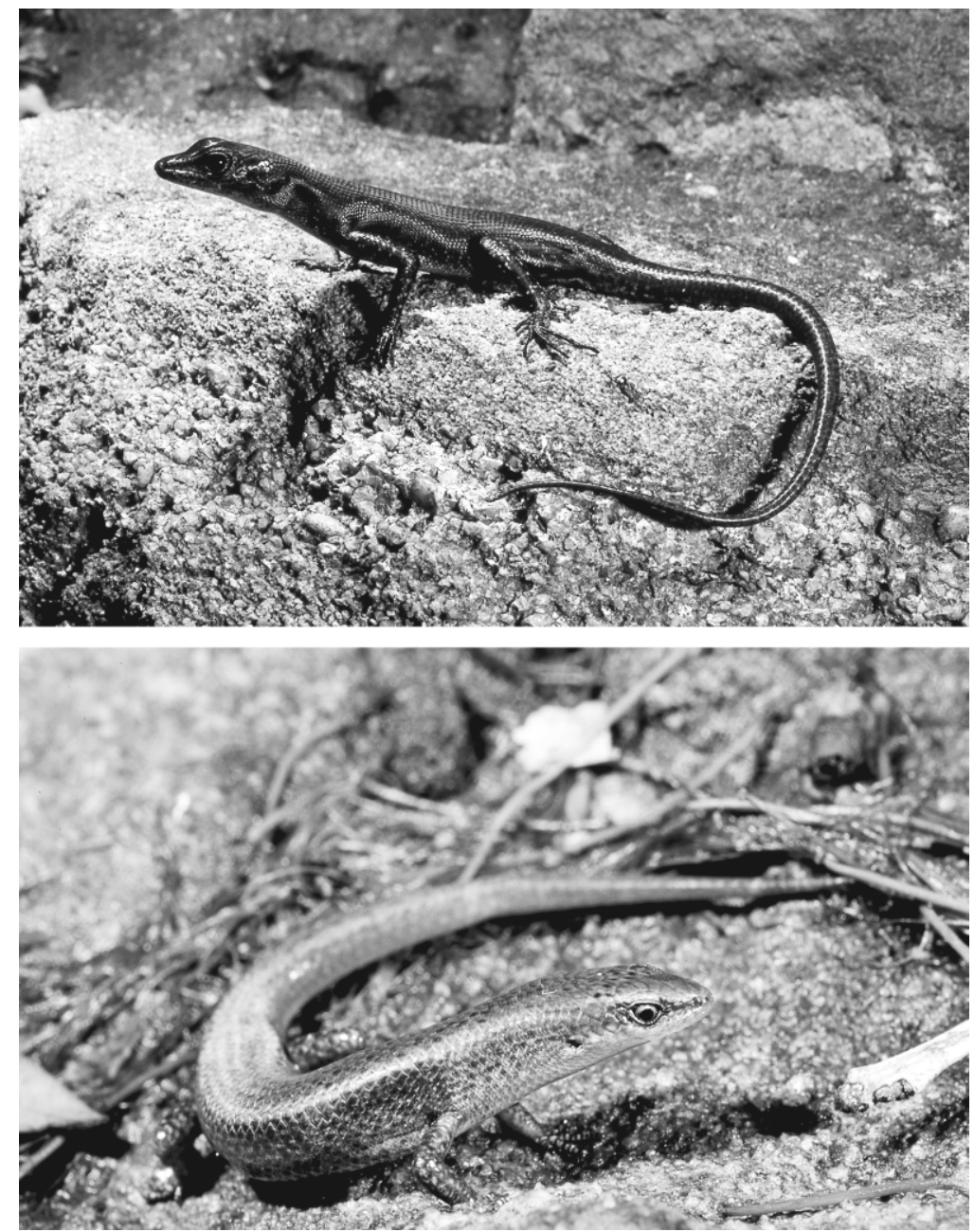

Plate 1. An example of the morphological differences between (top) a species that occupies habitats composed of large rocks and boulders, the Black Mountian rainbow skink (Carlia scirtetis), and (bottom) a species that predominantly uses habitats with large amounts of leaf litter and ground cover (Carlia laevis). Note the differences in fore- and hind-limb length, inter-limb length (the distance between the fore- and hind-limbs), and degree of body flattening between the two species. Photo credits: Eric Vanderduys.

of arboreal lizards (e.g., Anolis; Losos 1990, Toro et al. 2004, Irschick et al. 2005). An implicit assumption of studies relating morphology to performance is that behavior does not intervene to uncouple them (Garland and Losos 1994, Irschick 2002, Goodman 2007b, see Huey et al. 2003). Because behavior may alter how species perform under natural conditions, attempts to draw correlative links between field measures of habitat use and laboratory measures of performance may not be straightforward (e.g., Irschick 2002, Huey et al. 2003, Mattingly and Jayne 2004, Irschick et al. 2005). A behavior that may potentially alter selection on jump distances is if individuals jump while running, rather than jump from a standing start. In our study system, lizards in rocky habitat definitely evade capture by humans by jumping from rock to rock while running, whereas lizards in less rocky habitats usually enter cover immediately after dropping to the ground or running only short distances $(<0.5 \mathrm{~m}$; B. A. Goodman, personal observation). Thus, it seems plausible that selection may increase sprint speed in rocky habitats, which, in turn, enables individuals to bridge gaps in the habitat more effectively, without causing a selective increase in jump performance from a standing start. Alternatively, jump performance may be less related to limb length than to muscle physiology in these skinks, as species with different relative limb lengths from different habitats may jump similar distances (see Toro et al. 2004). A comparison of gecko species from two habitats (climbing vs. terrestrial) that require markedly different modes of locomotion identified no difference in limb length, suggesting habitat-induced shifts in limb morphology are not inevitable (Zaaf and Van Damme 2001).

In leaf litter, observations of feeding and fleeing lizards suggest that stealth for hunting prey and crypsis for avoiding predators are critical traits. Slower 
sprinting, climbing, and poorer clinging performance of species from leaf litter-dominated habitats confirm the intuitive possibility that fast sprinting, climbing, and clinging are not critical traits. Field observations indicate that, when disturbed, many leaf litter-dwelling species move slowly beneath available leaf litter, which substantially reduces the possibility of detection by auditory and visually oriented predators. Thus, there may be no selection for fast sprinting, clinging, and climbing when individuals are under cover or always very close to retreats. Instead, predation may be most critical on individuals of leaf litter species when under cover or in retreats, such that selection may operate more effectively on other predator avoidance mechanisms, such as enhanced chemosensory ability (Downes and Shine 1998, Downes 2002). As such, our laboratory measures of climbing, sprinting, and clinging apparently provide a good measure of important performance criteria for species that climb and cling, but there were no equivalent measures for important performance traits of species from leaf litter habitats (e.g., sinusoidal locomotion through leaf litter, ability to remain motionless, crypsis, etc.) taken in this study.

For effective movement through leaf litter, the greater limb length of rock-using species may interfere with locomotion. It is unknown whether rock-using species would experience reduced locomotor performance if forced to use such habitats. Species of the scincid genus Ctenotus from open habitats often have longer limbs than species from densely vegetated habitats (Pianka 1969). In some cases, long-limbed Ctenotus species are known to circumvent the problems associated with moving through dense vegetation by folding their legs back and using sinusoidal locomotion to push through dense spinifex grass (James 1989). However, whether such a locomotor strategy would be equally effective when attempting to move with minimal disturbance through leaf litter is unknown. Behavioral field observations of the rock-using species Carlia rococo and the generalist species $C$. longipes indicate that both species often run rapidly through small areas of leaf litter when pursued by a predator (B. A. Goodman, personal observation). Indeed, whether these species are equally effective at covering greater distances of leaf litter, or whether $C$. rococo (a rock specialist) experiences a negative effect on speed or maneuverability (Vanhooydonck and Van Damme 2003) when escaping in leaf litter habitat is unknown. Thus, greater limb length may not be maladaptive in leaf litter specialists, but may simply be under less intense natural selection, or selection may operate more intensely on other traits in leaf litter habitats, such as body elongation for enhanced sinusoidal locomotion (Wiens and Slingluff 2001, Navas et al. 2004), color pattern, or antipredator behavior (Brodie 1992).

Enhanced cling ability is likely to lead to increased climbing speed due to the need to cling well when climbing (Losos et al. 1993). It is possible that climbing and clinging are related to male reproductive success. Several species of Carlia display male combat, including C. jarnoldae, C. rubrigularis, and C. rostralis, that typically involves chasing and biting an opponent (Whittier and Martin 1992, Torr 1994, Langkilde and Schwarzkopf 2003). Individuals of C. scirtetis often chase and force conspecifics from specific boulders, which are presumably within defined territories (B. A. Goodman, personal observation). As the maintenance of specific territories may correlate directly with male fitness (Stamps et al. 1997, Huyghe et al. 2005, Husak et al. 2006), greater climbing, and therefore, clinging ability (Goodman et al. 2007), may be important performance traits linked to mating opportunities in rocky habitats. Thus, it would be worthwhile knowing whether males with increased climbing speed and clinging ability also experience increased reproductive success, due either to their enhanced ability to catch up to females for mating, or to defend and patrol territories (Hews 1990, Lappin and Husak 2005, Husak et al. 2006), if they are territorial.

The patterns identified in this study indicate that rocky habitats play an important role in the evolution of both morphology and performance of organisms that use them. While previous studies have focused in detail on the role of perch use and diameter in driving ecomorphological relationships, this is the first study to demonstrate that the availability of rocks is an important selective agent, and that the forces operating in this habitat are in some ways similar, but in other ways are quite different from forces operating on locomotion on narrow perches. In addition, we suggest that the performance measures usually used to assess performance in general are likely only relevant in certain habitats. Future studies could fruitfully explore the influence of other habitat gradients (e.g., subterranean and fossorial locomotion; Navas et al. 2004) based on a wider range of performance criteria to describe a fuller range of potential ecomorphological patterns in terrestrial vertebrates.

\section{ACKNOWLEDGMents}

This work was funded by a Linnean Society of New South Wales Ethel Mary Read Grant, the Royal Zoological Society of NSW, the Peter Rankin Trust Fund in Herpetology, and JCU supplemental Internal Research Grants to B. Goodman. We thank J. Isaac and B. D. Goodman for discussion. All animals were collected and maintained in captivity in accordance with QPWS Scientific Purposes Permit Number F1/000253/99/SAA and JCU Animal Ethics Permit Number A516.

\section{Literature Cited}

Arnold, S. J. 1983. Morphology, performance and fitness. American Zoologist 23:347-361.

Brodie, E. D., III. 1992. Correlational selection for color pattern and antipredator behavior in the garter snake Thamnophis ordinoides. Evolution 46:1284-1298.

Cogger, H. G. 2000. Reptiles and amphibians of Australia. Reed Books, Sydney, Australia.

Dolman, G., and C. Moritz. 2006. A multilocus perspective on refugial isolation and divergence in rainforest skinks (Carlia). Evolution 60:573-582. 
Downes, S. J. 2002. Does responsiveness to predator scents affect lizard survivorship? Behavioral Ecology and Sociobiology 52:38-42.

Downes, S. J., and R. Shine. 1998. Sedentary snakes and gullible geckos: predator-prey coevolution in nocturnal rockdwelling reptiles. Animal Behaviour 55:1373-1385.

Farley, C. T., and M. Emshwiller. 1996. Efficiency of uphill locomotion in nocturnal and diurnal lizards. Journal of Experimental Biology 199:587-592.

Garland, T., Jr., P. H. Harvey, and A. R. Ives. 1992. Procedures for the analysis of comparative data using phylogenetic independent contrasts. Systematic Biology 41:18-32.

Garland, T., Jr., and J. B. Losos. 1994. Ecological morphology of locomotor performance in squamate reptiles. Pages $240-$ 302 in P. C. Wainwright and S. M. Reilly, editors. Ecological morphology: integrative organismal biology. University of Chicago Press, Chicago, Illinois, USA.

Garland, T., Jr., P. E. Midford, and A. R. Ives. 1999. An introduction to phylogenetically based statistical methods, with a new method for confidence intervals on ancestral values. American Zoologist 39:374-388.

Goodman, B. A. 2007a. Microhabitat separation and niche overlap among five assemblages of tropical skinks. Australian Journal of Zoology 55:15-27.

Goodman, B. A. 2007b. Divergent morphologies, performance, and escape behaviour in two tropical rock-using lizards. Biological Journal of the Linnean Society 91:85-98.

Goodman, B. A., A. A. Krockenberger, and L. Schwarzkopf. 2007. Master of them all: performance specialization does not result in trade-offs in tropical lizards. Evolutionary Ecology Research 9:527-546.

Goodman, B. A., and G. N. L. Peterson. 2005. A technique for sampling lizards in rocky habitats. Herpetological Review 36: $41-43$.

Herrel, A., J. J. Meyers, and B. Vanhooydonck. 2002. Relations between microhabitat use and limb shape in phrynosomatid lizards. Biological Journal of the Linnean Society 77: 149-163.

Hews, D. K. 1990. Examining hypotheses generated by field measures of sexual selection on male lizards, Uta Palmeri. Evolution 44:1956-1999.

Huey, R. B. 1991. Physiological consequences of habitat selection. American Naturalist 137(Supplement):S91-S115.

Huey, R. B., P. E. Hertz, and B. Sinervo. 2003. Behavioral drive versus behavioral inertia in evolution: a null model approach. American Naturalist 161:357-366.

Husak, J. F., S. F. Fox, M. B. Lovern, and R. A. Van Den Bussche. 2006. Faster lizards sire more offspring: sexual selection on whole-animal performance. Evolution 60:2122 2130.

Huyghe, K., B. Vanhooydonck, H. Scheers, M. Molina-Borja and R. Van Damme. 2005. Morphology, performance and fighting capacity in male lizards, Gallotia galloti. Functional Ecology 19:800-807.

Ingram, G., and J. Covacevich. 1988. Revision of the genus Lygisaurus De Vs (Scincidae: Reptilia) in Australia. Memoirs of the Queensland Museum 25:335-354.

Ingram, G., and J. Covacevich. 1989. Revision of the genus Carlia (Reptilia, Scincidae) in Australia with comments on Carlia bicarinata of New Guinea. Memoirs of the Queensland Museum 27:443-490.

Irschick, D. J. 2002. Evolutionary approaches for studying functional morphology: examples from studies of performance capacity. Integrative and Comparative Biology 42: 278-290.

Irschick, D. J., and T. Garland. 2001. Integrating function and ecology in studies of adaptation: investigations of locomotor capacity as a model system. Annual Review of Ecology and Systematics 32:367-396.
Irschick, D. J., and B. C. Jayne. 1998. Effects of incline on speed, acceleration, body posture and hind-limb kinematics in two species of lizard Callisaurus draconoides and Uma scoparia. Journal of Experimental Biology 201:273-287.

Irschick, D. J., and J. B. Losos. 1999. Do lizards avoid habitats in which performance is submaximal? The relationship between sprinting capabilities and structural habitat use in caribbean Anoles. American Naturalist 154:293-305.

Irschick, D. J., B. Vanhooydonck, A. Herrel, and J. Meyers. 2005. Intraspecific correlations among morphology, performance and habitat use within a green anole lizard (Anolis carolinensis) population. Biological Journal of the Linnean Society 85:211-221.

Irschick, D. J., L. J. Vitt, P. A. Zani, and J. B. Losos. 1997. A comparison of evolutionary radiations in mainland and Caribbean Anolis lizards. Ecology 78:2191-2203.

Jackson, D. A. 1993. Stopping rules in principal components analysis: a comparison of heuristical and statistical approaches. Ecology 74:2204-2214.

James, C. D. 1989. Comparative ecology of sympatric scincid lizards (Ctenotus) in spinifex grass-lands of Central Australia. Ph.D. Dissertation. University of Sydney, Sydney, Australia.

Langkilde, T., and L. Schwarzkopf. 2003. Observations of mating behavior and reproduction in the scincid Carlia jarnoldae. Herpetological Review 34:325-326.

Lappin, A. K., and J. F. Husak. 2005. Weapon performance, not size, determines mating success and potential reproductive output in the collard lizard (Crotaphytus collaris). American Naturalist 166:426-436.

Losos, J. B. 1990. Ecomorphology, performance capability and scaling in West Indian Anolis: An evolutionary analysis. Ecological Monographs 60:369-388.

Losos, J. B. 1995. Community evolution in Greater Antillean Anolis lizards: phylogenetic patterns and experimental tests. Philosophical Transactions of the Royal Society of London B 349:69-75.

Losos, J. B., and D. J. Irschick. 1996. The effect of perch diameter on escape behaviour of Anolis lizards: laboratory predictions and field tests. Animal Behaviour 51:593-602.

Losos, J. B., P. L. F. N. Mouton, R. Bickel, I. Cornelius, and L. Ruddock. 2002. The effect of body armature on escape behaviour in cordylid lizards. Animal Behaviour 64:313-321.

Losos, J. B., and B. Sinervo. 1989. The effects of morphology and perch diameter on sprint performance of Anolis lizards. Journal of Experimental Biology 245:23-30.

Losos, J. B., B. M. Walton, and A. F. Bennett. 1993. Trade-offs between sprinting and clinging ability in Kenyan Chameleons. Functional Ecology 7:281-286.

Losos, J. B., K. I. Warheit, and T. W. Schoener. 1997. Adaptive differentiation following experimental island colonization in Anolis lizards. Nature 387:70-72.

Mattingly, W. B., and B. C. Jayne. 2004. Resource use in arboreal habitats: structure affects locomotion of four ecomorphs of Anolis lizards. Ecology 85:1111-1124.

Melville, J., and R. Swain. 2000. Evolutionary relationships between morphology, performance, and habitat openness in the lizard genus Niveoscincus (Scincidae: Lygosominae). Biological Journal of the Linnean Society 70:667-683.

Miles, D. B., and R. E. Ricklefs. 1984. The correlation between ecology and morphology in deciduous forest passerine birds. Ecology 65:1629-1640.

Moermond, T. C. 1979. Habitat constraints on the behavior, morphology, and community structure of Anolis lizards. Ecology 60:152-164.

Navas, C. A., M. M. Antoniazzi, J. E. Carvalho, J. G. ChauiBerlink, R. S. James, C. Jared, T. Kohlsdorf, M. D. PaiSilva, and R. S. Wilson. 2004. Morphological and physiological specialization for digging in amphisbaenians, an ancient lineage of fossorial vertebrates. Journal of Experimental Biology 207:2433-2441. 
Phillips, B. L., S. J. E. Baird, and C. Moritz. 2004. When vicars meet: a narrow contact zone between morphologically cryptic phylogeographic lineages of the rainforest skink, Carlia rubrigularis. Evolution 58:1536-1548.

Pianka, E. R. 1969. Sympatry of desert lizards (Ctenotus) in Western Australia. Ecology 50:1012-1030.

Pounds, J. A. 1988. Ecomorphology, locomotion, and microhabitat structure: patterns in a tropical mainland Anolis community. Ecological Monographs 58:299-320.

Revell, L. J., M. A. Johnson, J. A. I. Schulte, J. J. Kolbe, and J. B. Losos. 2007. A phylogenetic test for adaptive convergence in rock-dwelling lizards. Evolution 61:28982912.

Schneider, C. J., T. B. Smith, B. Larison, and C. Moritz. 1999. A test of alternative models of diversification in tropical rainforests: ecological gradients vs. rainforest refugia. Proceedings of the National Academy of Sciences USA 96: 13869-13873.

Schulte, J. A., J. B. Losos, F. B. Cruz, and H. Nunez. 2004. The relationship between morphology, escape behaviour and microhabitat occupation in the lizard clade Liolaemus (Iguanidae: Tropidurinae: Liolaemini). Journal of Evolutionary Biology 17:408-420.

Sinervo, B., and J. B. Losos. 1991. Walking the tight rope: a comparison of arboreal sprint performance among populations of Sceloporus occidentalis. Ecology 72:1225-1237.

Sokal, R. S., and F. J. Rohlf. 1995. Biometry. Third edition. Freeman, New York, New York, USA.

Stamps, J. A., J. B. Losos, and R. E. Andrews. 1997. A comparative study of population density and sexual size dimorphism in lizards. American Naturalist 149:64-90.

Taylor, C. R., S. L. Caldwell, and V. J. Rowntree. 1972. Running up and down hills: some consequences of size. Science 178:1096-1097.

Toro, E., A. Herrel, and D. J. Irschick. 2004. The evolution of jumping performance in Caribbean Anolis lizards: solutions to biomechanical trade-offs. American Naturalist 163:844-856.

Torr, G. A. 1994. Combat behaviour in the rainforest skink Carlia rubrigularis. Herpetofauna 24:40.
Turchin, P. 1998. Quantitative analysis of movement: measuring and modeling population redistribution in animals and plants. Sinauer Associates, Sunderland, Massuchusetts, USA.

Van Damme, R., P. Aerts, and B. Vanhooydonck. 1998. Variation in morphology, gait characteristics and speed of locomotion in two populations of lizards. Biological Journal of the Linnean Society 63:409-427.

Vanhooydonck, B., and R. Van Damme. 1999. Evolutionary relationships between body shape and habitat use in lacertid lizards. Evolutionary Ecology Research 1:785-805.

Vanhooydonck, B., and R. Van Damme. 2001. Evolutionary trade-offs in locomotor capacities in lacertid lizards: are splendid sprinters clumsy climbers? Journal of Evolutionary Biology 14:46-54.

Vanhooydonck, B., and R. Van Damme. 2003. Relationships between locomotor performance, microhabitat use and antipredator behaviour in lacertid lizards. Functional Ecology 17:160-169.

Vervust, B., I. Grbac, and R. Van Damme. 2007. Differences in morphology, performance and behaviour between recently diverged populations of Podarcis sicula mirror differences in predation pressure. Oikos 116:1343-1352.

Vitt, L. J., P. A. Caldwell, P. Zani, and T. A. Titus. 1997. The role of habitat shift in the evolution of lizard morphology: evidence from tropical Tropidurus. Proceedings of the National Academy of Science USA 94:3828-3832.

Whittier, J. M., and J. Martin. 1992. Aspects of social behaviour and dominance in male rainbow skinks, Carila rostralis. Australian Journal of Zoology 40:73-79.

Wiens, J. J., and J. L. Slingluff. 2001. How lizards turn into snakes: a phylogenetic analysis of body-form evolution in Anguid lizards. Evolution 55:2303-2318.

Zaaf, A., and R. Van Damme. 2001. Limb proportions in climbing and ground dwelling geckos (Lepidosauria, Gekkonidae): a phylogenetically informed analysis. Zoomorphology 121:45-53.

Zani, P. A. 2000. The comparative evolution of lizard claw and toe morphology and clinging performance. Journal of Evolutionary Biology 13:316-325.

\section{APPENDIX A}

A table showing (a) mean morphological traits and (b) mean limb morphology traits \pm standard error (mm) for 19 species representing 23 populations (Ecological Archives E089-197-A1).

\section{APPENDIX B}

A table showing mean performance ability \pm standard error for 19 species representing 23 populations (Ecological Archives E089-197-A2).

\section{APPENDIX C}

Phylogenetic relationships and phylogeny construction (Ecological Archives E089-197-A3). 